Canadian

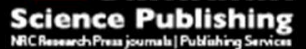

Canadian Journal of Civil Engineering Revue canadienne de génie civil

\title{
A Conditioning Method to Evaluate Moisture Influence on the Durability of Asphalt Mixture Materials
}

\begin{tabular}{|r|l|}
\hline Journal: & Canadian Journal of Civil Engineering \\
\hline Manuscript ID & cjce-2016-0153.R1 \\
\hline Danuscript Type: & Article \\
\hline Complete List of Authors: & $\begin{array}{l}\text { Diab, Aboelkasim; Aswan University, Civil Engineering } \\
\text { Sangiorgi, Cesare; University of Bologna, Department of Civil, Chemical, } \\
\text { Engironmental and Materials Engineering } \\
\text { Enieb, Mahmoud ; Assiut University, Civil Engineering } \\
\text { You, Zhanping; Michigan Technological University, Civil and Environmental } \\
\text { Engineering }\end{array}$ \\
\hline Keyword: & $\begin{array}{l}\text { Moisture Damage, Conditioning, Field Conditions, Durability, Asphalt } \\
\text { Pavements }\end{array}$ \\
\hline & \\
\hline
\end{tabular}




\title{
A Conditioning Method to Evaluate Moisture Influence on the Durability of Asphalt Mixture Materials
}

\author{
A. Diab $^{\mathrm{a},{ }^{*}}$, C. Sangiorgi ${ }^{\mathrm{b}}$, M. Enieb ${ }^{\mathrm{c}}$, Z. You $^{\mathrm{d}}$ \\ ${ }^{\mathrm{a}}$ Assistant Professor, Department of Civil Engineering, Aswan University, Egypt, daali@mtu.edu \\ ${ }^{\mathrm{b}}$ Assistant Professor, Department of Civil, Chemical, Environmental and Materials Engineering, \\ University of Bologna, Italy, cesare.sangiorgi4@unibo.it \\ ${ }^{\mathrm{c}}$ Assistant Professor, Department of Civil Engineering, Assiut University, Egypt, \\ m.enieb@aun.edu.eg \\ ${ }^{\mathrm{d}}$ Professor, Department of Civil and Environmental Engineering, Michigan Technological \\ University, Michigan, US, zyou@mtu.edu
}

\section{Corresponding author:}

Cesare Sangiorgi

Department of Civil, Chemical, Environmental and Materials Engineering, University of Bologna, Viale Risorgimento 2, Bologna, Italy, +390512093526, cesare.sangiorgi4@unibo.it 
Abstract: Over the years, researchers have developed many laboratory methods for conditioning and evaluating the moisture damage of asphalt mixtures. Most of the tests do not fully simulate field conditions and the evaluation criterion does not always predict the long-term susceptibility to moisture damage. This paper aims to present a comprehensive conditioning and evaluation method that simulates field conditions to assess the durability of bituminous layers against moisture damage. The equipment consists of a system applying a cyclic load on samples in which water can be forced through. The assessment procedure is based on the Indirect Tensile Strength (ITS) test after the conditioning method, from which the concept of the Damage Rate $\left(D_{r}\right)$ as an indicator for classifying the durability of mixtures against moisture damage, was developed. The method would allow asphalt practitioners to evaluate the mixture for susceptibility to moisture on a routine basis.

Keywords: Asphalt Pavements, Moisture Damage, Conditioning, Field Conditions, Durability 


\section{Introduction}

Moisture-induced damage of asphalt mixture materials is a complex issue and one of the primary challenges for pavement engineers. It is influenced by different variables including aggregate characteristics, asphalt binder rheological properties, production and construction technologies, type of mixture, and traffic and environmental effects during/after construction (Hicks 1991). Stripping is the most widely recognized term that is caused by moisture damage and is defined as the gradual loss of bonding between asphalt binder and aggregates and, consequently, influences the material's durability. Stripping within the asphalt-aggregate systems causes serious failures and distresses in pavement structure. Generally, there are six possible contributing mechanisms associated with moisture-induced damage of bituminous materials, namely detachment, spontaneous emulsification displacement, pore pressure induced damage, hydraulic scour, and environmental effects on the asphalt-aggregate system. However, it is worth mentioning that moisture damage is not governed by a single mechanism, but rather it is a consequence of different mechanisms (Little and Jones IV 2003). In spite of the fact that a lot of progress has been accomplished in clarifying the mechanisms of moisture damage, a sound and useful routine method for simulating it in the laboratory is lacking. Generally, all laboratory testing methods that evaluate the susceptibility to moisture damage of asphalt mixtures include utilizing water soaking or some type of moisture conditioning procedure. A number of conditioning processes used today to induce moisture damage in asphalt concrete samples, among them are: soaking in water for $24 \mathrm{~h}$ at $60{ }^{\circ} \mathrm{C}$, or freeze-thaw cycles at $-18{ }^{\circ} \mathrm{C}$ for $16 \mathrm{~h}$, and $60{ }^{\circ} \mathrm{C}$ water bath for $24 \mathrm{~h}$ (Krishnankuttynair 2008). Being that the specimens are considered conditioned after these processes, all the samples are brought to a constant temperature and prepared to undergo the testing protocol to assess the moisture susceptibility based on the selected design criterion. 
Despite their popularity, these methods of conditioning usually originate from practical experience and often lack fundamental basis or reference to field-like conditions.

During the last several years there have been huge exploration endeavors toward the development of a Simple Performance Test (SPT) (You and Dai 2007; Goh and You 2009; Goh et al. 2010) to match the Superpave ${ }^{\mathrm{TM}}$ design requirements for moisture damage. The commonly used methodology to evaluate the moisture susceptibility of asphalt concrete mixtures is the American Association of State Highway Transportation Officials (AASHTO) T-283. The T-283 mainly evaluates the Tensile Strength Ratio (TSR) of conditioned specimens to unconditioned specimens of the same mixture. In spite of its points of interest and ubiquity, there have been progressive studies to develop an alternative method to the T-283. The Hamburg Wheel Tracking (HWT) device, the SPT, and the road test machine have been evaluated as alternatives (Hurley and Prowell 2006; Bhusal 2008; Woodward et al. 2016). Recently, the Moisture Induced Stress Tester (MIST) has been developed as an attempt to provide faster and field-like conditions of moisture damage, however, the mechanisms of moisture damage are not well verified in the conditioning process; also, the damage mechanism after conditioning is not based on reliable criterion (Rowe et al. 2015). Also, the Saturation Aging Tensile Stiffness (SATS) test was developed in the UK as an asphalt durability test; it utilizes combined ageing/moisture damage conditioning procedure prior to mechanical testing. Although the SATS is able to replicate moisture damage stiffness reduction in the field it still has concerns such as the applicability to different asphalt mixtures (Grenfell et al. 2012). In addition, no cyclic stresses based on vehiclepavement interaction, extended period of time, and a fundamental evaluation of the mixtures after the conditioning process is still lacking (Rowe et al. 2015). 
Although the previously stated six mechanisms of moisture damage are usually connected with the effect of moisture to some extent, basically, the displacement and detachment do not require moisture to occur. Typically, the mechanisms associated with moisture damage are not fully addressed and happen over a drawn out stretch of time in the field. Based on Majidzadeh and Brovold (1996), the pore pressure from traffic loads can cause failures to the binder-to-aggregate bond. The initial water is in cyclic motion and significant pore pressure generates under traffic loading. It was stated that hydraulic scouring, as a consequence of repeated generation of pore pressure, is thought to be the essential cause of moisture-induced damage in asphalt pavements (Mallick et al. 2003). The good laboratory-based conditioning system ought to quicken the infiltration of moisture through asphalt coating to induce damage; thus differentiate mixtures that can resist moisture damage from those known to be susceptible (Kanitpong 2004; Birgisson et al. 2005; Zaniewski 2006).

\section{Research Objective}

This study aims to develop a quick performance-related procedure to evaluate the durability of asphalt mixtures against moisture damage. Several efforts have been spent so far to engender a procedure that would accurately determine the susceptibility of an asphalt mixture to moisture influence. None are widely accepted due to the complication of the process, unusual equipment, lack of consistent results or lack of connectivity with field conditions. In addition, the T-283 test routinely utilized for moisture damage testing has several drawbacks. Above all, it is time consuming, which is not conducive for production quality control and assurance testing. The mixture components change due to production variability, and the current methods do not predict moisture susceptibility of the mixture on a timely basis. Additionally, the application of different 
water saturation levels can result in wide variability in TSR results. Moreover, the T-283 does not replicate the combined effects of the contributing mechanisms that associate with moistureinduced damage. Finally, a TSR value of a specific mixture does not indicate any evidence that the moisture susceptibility of the tested mixture will satisfactorily match the desired criterion in the long-term.

The proposed procedure was developed based on the fact that the effect of water only on asphalt specimens does not fully simulate realistic conditions and, therefore, is not the best for evaluating moisture damage. In fact, considering the effect of traffic loading is essential. The effect of environmental conditions (temperature, moisture), along with traffic loading is, therefore, given as the laboratory simulation of the in-service conditions. In this paper, the damage rate of a mixture strength has been used as an alternative to distinguish the durability of asphalt mixtures against the susceptibility to moisture influence. The proposed procedure was adopted to evaluate and rank mixtures prepared with five different aggregates.

\section{Proposed methodology and testing procedure}

The proposed conditioning system consists of a temperature-controlled water bath (see Figure 1) where a maximum of three Marshall size samples are to be submerged. To generate repeated pore pressure, a rigid steel plate applies a sinusoidal cyclic loading to the samples by a Universal Testing Machine (UTM). A perforated rubberized sheet is placed on the concrete samples while conditioning to avoid crushing the aggregates and simulate vehicle tire-asphalt layer contact. The selected cyclic pressure corresponds to the range of expected water pressure in field conditions combined with a relatively high temperature (e.g. $50{ }^{\circ} \mathrm{C}$ ) to simulate the field conditions that could induce moisture damage within a short period of time. The ITS tests are then performed 
after $\mathrm{T}_{\mathrm{i}-1}$ and $\mathrm{T}_{\mathrm{i}}$ conditioning times for the same samples. The expected relationship between the conditioning time and ITS values is shown in Figure 2.

Figure 1: Schematic Representation of the Proposed Conditioning System

Figure 2: Expected Relationship between ITS and Conditioning Time

\section{Background and Theoretical Basis of the Proposed Procedure}

\subsection{Cyclic Loading (Magnitude and Frequency)}

The applied cyclic loading should be selected to portray a real loading that causes dynamics of pressures and scouring encountered in the field with repeated pore pressure caused by vehicle tires passing over wet pavement. Novak et al. (2002), among others, investigated the effect of a mixture's permeability and vehicle speed on pore pressure in pavements. Novak et al. calculated the pore pressure for different values of permeability and vehicle speed. A $0.2 \mathrm{sec}$ loading time caused a significant reversal of pore pressure, ranging between 200 and $600 \mathrm{kPa}$ at the top of the pavement surface. A negative pore pressure or suction was registered as the solid skeleton recuperated from its deformed shape and water was sucked into the vacuum space. This phenomenon is hypothesized to engender hydraulic scouring which contributes to the moisture damage of the asphalt-aggregate system. The increase in permeability of the top of the asphalt layer reduces the pore pressure. Jimenez (1974) presented a method to quantify the stripping susceptibility of asphalt paving mixtures due to the effect of pore pressure. First the specimens were vacuum saturated in a $50{ }^{\circ} \mathrm{C}$ water bath then tested. The saturated specimens were then subjected to conditioning by applying cyclic water pressure at a frequency of $10 \mathrm{~Hz}$. The cyclic 
pressure caused pore water pressure in a range of 35 to $207 \mathrm{kPa}$. The saturated specimens were stressed for 5800 repetitions in 10 minutes. The applied pressure was selected in a range comparable to the expected water pressure in field conditions.

\subsection{Conditioning Temperature}

The conditioning temperatures utilized for the traditional conditioning systems are generally arbitrary and do not have a consistent correlation with real pavement conditions. For example, in the T-283 test the conditioning temperature, $60{ }^{\circ} \mathrm{C}$, is fixed for all pavement environments. In a study conducted by Terrel and Al-Swailmi (1994) for the determination of water sensitivity of asphalt mixtures, the selected temperatures were: 60,25 and $-18{ }^{\circ} \mathrm{C}$. It can be found in the literature that there is no theoretical basis to correlate the field conditions with the desired conditioning in the laboratory. Furthermore, the commonly used freeze-thaw system of conditioning could be defined as a short-term conditioning because it considers environmental effects within one year.

\subsection{Concept of Damage Rate $\left(D_{r}\right)$}

To quantitatively assess the moisture damage of an asphalt mixture, the subsisting evaluation methods generally use one criterion as an indicator for pavement designers (for instance the TSR). Not taking into account how the pavement actually performs after a long time of moisture conditioning, the moisture susceptibility of mixtures may still satisfactorily match the criterion.

The water damage of asphalt layers can be due to the loss of cohesion and/or loss of adhesion and aggregate degradation (Figure 3). However, the loss of cohesion and adhesion are 
paramount to the process of stripping. A reduction in cohesion and/or adhesion of asphalt binder results in a reduction in the overall strength or stiffness of the mixture.

Figure 3: Possible Failures of Asphalt Mixtures subjected to Moisture: (a) Cohesive Failure, (b) Adhesive Failure, and (c) Aggregate Degradation

On the light of the above, this research suggests the $D_{r}$ as an indicator to evaluate the long-term moisture damage of compacted samples. The concept of the $\mathrm{D}_{\mathrm{r}}$ presented herein is based on the following hypotheses:

- Inducement of pore pressure within the air voids of the compacted asphalt specimen due to the combined effect of cyclic loading and temperature.

- Pore pressure could exceed the adhesive and/or cohesive strength within the binderaggregate system, therefore increasing the air voids in the conditioned specimen.

- The conditioning procedure does not cause astringent damage to the compacted specimen, and the specimen is still useable for testing after conditioning.

These assumptions are based on the fact that the distribution of air voids in an asphalt concrete sample provides the means by which moisture can enter the mixture (Khosla and Harikrishnan 2007). While conditioning, the air void content of a compacted asphalt sample experiences diverse stages. The asphalt mixture is designed for a target air void content by adjusting the aggregate size, gradation, and the asphalt binder content; and along these lines, a range of porosity would bring about the dry designed mixture. The compacted sample would be viewed as almost impermeable in the event that it has significant air voids that are not interconnected. At 
the point when the air void content increments pass a critical value, the air voids would be bigger and interconnected; this permits water to infiltrate through the layer. In the range between impermeable and open or draining blends, is where most asphalt pavement layers are compacted. The air voids tend to range from small to large, with a range of porosity relying upon their interconnection (Terrel and Al-Swailmi 1994). Once moisture exists in voids of an asphalt mixture, it interacts with the asphalt-aggregate interface. Conceptually, as the damage related to moisture increases, the air voids increment. Therferore, there is a solid relationship between conditioning time and change in air voids. Consequently, the proportion of air voids can be considered as a pointer to assess the moisture damage of the compacted mixtures.

The flow time $(\mathrm{T})$ of water through the air voids in the asphalt mixture can be expressed as a function of water volume (V) and flow rate (Q) as follows:

$\mathrm{dT}=\frac{\mathrm{dV}}{\mathrm{Q}}$

From Figure 2, the total flow time $(\Delta \mathrm{T})$ can be written as follows:

$\Delta \mathrm{T}=\int_{V_{i-1}}^{V_{i}} \frac{\mathrm{dV}}{\mathrm{Q}}=\frac{V_{i}-V_{i-1}}{\mathrm{Q}}$

in which $\mathrm{V}_{\mathrm{i}-1}$ is the initial (i.e. after compaction) volume of air voids or after a time i-1 of conditioning; and $\mathrm{V}_{\mathrm{i}}$ is the volume of saturated air voids after a time $\mathrm{i}$ of conditioning. 
The mechanisms resulting from moisture damage reduce the strength of the mixture. Then, the $\mathrm{D}_{\mathrm{r}}$, defined as the change of the ITS with respect to time of conditioning (Figure 2), can be expressed as:

$\mathrm{D}_{\mathrm{r}}=\frac{\mathrm{ITS}_{\mathrm{i}-1}-\mathrm{ITS}_{\mathrm{i}}}{\Delta \mathrm{T}}$

Equations (2) and (3) yield:

$\mathrm{D}_{\mathrm{r}}=\mathrm{Q}\left(\frac{\mathrm{ITS}_{\mathrm{i}-1}-\mathrm{ITS}_{\mathrm{i}}}{V_{i}-V_{i-1}}\right)$

\section{Experimental Program}

The experimental testing program is divided into three stages: specimen fabrication, conditioning, and evaluation. The whole check of the proposed strategy in this made use of Marshall specimens fabricated in the laboratory from five types of aggregate in accordance with the standard method (ASTM D6926 2004). The proposed experimental program provides information to evaluate the relative performance of the five aggregates-prepared mixtures and verification of the proposed method. The five aggregates used (sandstone, gravel, dolomite, basalt, and limestone) were all supplied by aggregate industries from various quarries situated in Egypt. The various mineral constituents of the selected aggregates bring about various moisture sensitivity of their blends, from which the ability of the created system to dependably recognize moisture damage can be confirmed. Commonly, aggregates are classified as either acidic, which are characterized as hydrophilic, or basic aggregates (considered to be hydrophobic) (Tarrar and Wagh 1992; Kanitpong and Bahia 2003; Bhasin 2006). Since the asphalt binder is weakly acidic 
in nature, the acidic aggregates are more susceptible to moisture damage, while basic aggregates are less susceptible to moisture damage. Based on the information provided from the literature (Bhasin et al. 2005; Hurley and Prowell 2005; Bhasin et al. 2007), the studied aggregates can be ranked as acidic (sandstone and gravel) and the rest are basic aggregates. Table $\mathbf{1}$ shows the percent passing for the selected aggregates gradation as well as the specification requirements. Bitumen 60/70 penetration (determined according to ASTM D5 (ASTM D5-97 1998) commonly used in Egypt was used to prepare all Marshall samples. The physical properties of the asphalt binder are given in Table 2. All aggregate blends were dense graded. The target asphalt binder content was $5.50 \%$ for all mixtures, as the difference in the optimal content of asphalt of the five mixtures was negligible. All bituminous mixtures were first mixed at $165{ }^{\circ} \mathrm{C}$, then ovenconditioned for two hours at $152{ }^{\circ} \mathrm{C}$, and finally compacted with the Marshall compactor to a target air void content of $4 \%$. The rotational viscosity test following the standard procedure (AASHTO T316-11 2011) was adopted to determine the mixing and compaction temperatures of the mixtures. After an overnight cool-down to room temperature, the Marshall samples were first conditioned and then tested.

The ITS test was used to determine the tensile strength of dry Marshall samples at $25{ }^{\circ} \mathrm{C}$ according to ASTM D4123 (ASTM D4123-82 1999). The load was applied at a vertical displacement rate of $4 \mathrm{~mm} / \mathrm{min}$, from which the ITS defined as the maximum stress at the center of the specimen in the radial direction during loading that can be calculated. A set of three samples from each mixture were conditioned according to the proposed conditioning method. The specimens were placed in the conditioning unit then submerged in water; a perforated rubberized mat was placed on top of the asphalt samples prior to applying cyclic loading on the 
upper steel plate. The steel plates are sufficiently inflexible to disperse the applied pressure consistently on the surface of the three samples. After water was heated to $50{ }^{\circ} \mathrm{C}$ in the conditioning unit, a sinusoidal cyclic pressure of $200 \mathrm{kPa}$ with a frequency of $10 \mathrm{~Hz}$ was applied by the UTM (Figure 4). After $30 \mathrm{~min}$ of conditioning, the specimens were bagged and placed into a water bath at $25{ }^{\circ} \mathrm{C}$ for $2 \mathrm{hrs}$, then dried before ITS testing. It is worth mentioning that at first, different conditioning times have been utilized on trial samples to choose an effective conditioning time $(30 \mathrm{~min})$ that was able to induce sufficient damage or affect the strength of the samples. As the conditioning time is a cause of significant distinction in the results, a small difference in the ITS results have been noticed between short conditioning times (less than 30 min). Finally, another set of samples including three samples for each mixture, have been subjected to the same process of conditioning and testing after $60 \mathrm{~min}$.

Figure 4: Conditioning Process: (a) UTM, (b) Samples inside the Conditioning Unit, (c) Rubberized Sheet

The average air voids ratio for each set (unconditioned and after 30 or 60 min conditioning) was calculated by means of approximate standard test methods using computed bulk specific gravity (ASTM D2726 2011) and maximum theoretical gravity (ASTM D2041 2011) for each mixture. Practically, the TSR is used as a criterion to distinguish the susceptibility to moisture damage for different asphalt mixtures. Therefore, the moisture sensitivity of all the studied mixtures was evaluated by performing the TSR test as per AASHTO T-283 standard (AASHTO T283-14 2014). The TSR values were calculated for all the studied mixtures. For the TSR testing, another 
set of the samples (three samples for each mixture) was conditioned adding one freeze-thaw cycle.

\section{Discussion}

Figure 5 provides the average values of the ITS from three replicates of dry and conditioned samples (after 30 and 60 min conditioning) for the five mixtures. The error bars in the figure represent the standard deviation of the individual test results from the average. The conditioning (i.e. combined effect of moisture and cyclic loading) of asphalt samples causes more moisture to infiltrate the mixture, which in turn causes a loss of overall strength. The figure demonstrates that the strength of the mixtures diminishes with the increase in conditioning time. Therefore, the suggested method of conditioning is effective in simulating moisture induced damage in the laboratory.

Figure 5: ITS vs. Conditioning Time for Five Asphalt Mixtures

From the believe that the air void content variation due to moisture damage can influence the behavior and performance of asphalt mixtures (Terrel and Al-Swailmi 1994), its effects were also studied herein. Figure 6 shows a plot of the air void content for dry and conditioned samples for the five mixtures. From Figures 5 and $\mathbf{6}$ a clear trend of decreasing strength with an increase in air voids content is registered. This is consistent with Jimenez's (1974) observation of decrease in strength with an increase in water permeable voids. As the air voids distribution in the asphalt concrete provides the means by which moisture can diffuse into the mixture, therefore, the change of air voids can be actually used as an indirect indicator of moisture damage. 
Figure 6: Air Voids vs. Conditioning Time for Five Asphalt Mixtures

Finally, in the AASHTO T 283 test, a minimum TSR of $80 \%$ is specified as the passing limit and is used as an indicator of stripping susceptibility of asphalt concrete mixtures. A comparison between the TSR and $D_{r}$ values is shown in Figure 7. It is clear that the TSR and $D_{r}$ are inversely related. From all the results it can be seen that basic aggregates experienced less damage compared to the acidic aggregates. This finding appears to correlate well with the results from another study (Diab et al. 2014). The method was therefore proven able to distinguish between the durability of the studied mixtures. For instance, it can be seen that, according to the proposed method, the dolomite mixture is more durable than the gravel prepared mixture.

Figure 7: $D_{r}$ vs. TSR for Five Asphalt Mixtures: (a) after 30 min. conditioning, and (b) after an hour conditioning

\section{Summary and Conclusions}

The TSR test alone cannot predict the long-term performance of the asphalt mixtures against the in-service conditions experienced on asphalt pavements and, consequently, cannot fully predict their durability to water damage. The repeated loading in addition to reasonable environmental conditioning can both help water diffuse into the asphalt mixture which, in turn, weakens the binding film; therefore, adhesive and/or cohesive failures and aggregate degradation occurs.

The objective of this study was to develop a quick and reliable methodology for the evaluation of moisture susceptibility of in-service asphalt paving mixtures. Preliminary tests indicated that the 
conditioning process of applying cyclic pressure to submerged compacted specimens can induce moisture damage. A $200 \mathrm{kPa}$ pressure was chosen in light of the expected water pressure in saturated pavement under traffic subjected to a relatively high temperature $\left(50{ }^{\circ} \mathrm{C}\right)$ to simulate the conditions that could induce moisture damage within a reasonable amount of time. As it was demonstrated from past studies that the viable conditioning procedure ought to represent the field damaging mechanisms of moisture, the current research proposed a new technique to dependably simulate field conditions in the lab scale.

This method suggested using the damage rate $\left(D_{r}\right)$ as an indicator of moisture susceptibility to account for the effects of conditioning in the long-term. The $\mathrm{D}_{\mathrm{r}}$ value can be determined from the laboratory after testing the ITS sample using two different conditioning periods. The lower the $\mathrm{D}_{\mathrm{r}}$, the better resistance to moisture damage of the asphalt mixture.

The developed system was able to rank the behavior of various asphalt mixtures prepared with five aggregate types that have different moisture susceptibility history. So far, it is not possible to define a threshold value that can be used in the mixture screening test. The proposed procedure would have a good potential for contributing to the evaluation of the durability of asphalt mixtures against moisture influence.

\section{References}

AASHTO T283-14. 2014. Standard Method of Test for Resistance of Compacted Asphalt Mixtures to Moisture-Induced Damage. AASHTO, Washington DC.

AASHTO T316-11. 2011. Viscosity Determination of Asphalt Binder Using Rotational Viscometer. AASHTO Standard Specifications for Transportation Materials and Methods of Sampling and Testing. Washington DC. 
ASTM D5-97. 1998. Standard test method for penetration of bituminous materials. Annual Book of ASTM Standards, Vol.04.03, Philadelphia 19103-1187.

ASTM D4123-82. 1999. Standard Test Method for Indirect Tension Test for Resilient Modulus of Bituminous Mixtures. Annual Book of ASTM Standards Vol.04.03, ASTM International, Philadelphia, US.

ASTM D6926. 2004. Standard Practice for Preparation of Bituminous Specimens Using Marshall Apparatus. Annual Book of ASTM Standards, American Society for Testing and Materials.

ASTM D2041. 2011. Standard test method for theoretical maximum specific gravity and density of bituminous paving mixtures. West Conshohocken, PA, ASTM International.

ASTM D2726. 2011. Standard Test Method for Bulk Specific Gravity and Density of NonAbsorptive Compacted Bituminous Mixtures. West Conshohocken, PA, ASTM International.

Bhasin, A. 2006. Development of methods to quantify bitumen-aggregate adhesion and loss of adhesion due to water. Ph.D. Thesis, Texas A\&M University, College Station, Texas.

Bhasin, A., Button, J. W. and Chowdhury, A. 2005. Evaluation of selected laboratory procedures and development of databases for HMA. Report No. FHWA=TX-05=0-4203-3, Texas Transportation Institute, College Station, TX.

Bhasin, A., Little, D. N., Vasconcelos, K. L. and Masad, E. 2007. Surface free energy to identify moisture sensitivity of materials for asphalt mixes. Transp. Res. Rec., Vol. 2001, pp. 37-45.

Bhusal, S. 2008. A laboratory study of warm mix asphalt for moisture damage potential and performances issues. Master thesis. Oklahoma State University.

Birgisson, B., Roque, R., Tia, M. and Masad, E. 2005. Development and Evaluation of Test Methods to Evaluate Water Damage and Effectiveness of Anti-Stripping Agents. Chapters 2, 3, 
6. University of Florida Project No. 4910-4504-722-12. Florida Department of Transportation,Tallhassee,FL.http://www.dot.state.fl.us/researchcenter/Completed_Proj/Summar y_SMO/FDOT_BC354_11_rpt.pdf.

Diab, A., You, Z., Hossain, Z. and Zaman, M. 2014. Moisture susceptibility evaluation of nanosized hydrated lime-modified asphalt-aggregate systems based on surface free energy concept. Transportation Research Record 2446, p52-59.

Goh, S. W. and You, Z. 2009. A simple stepwise method to determine and evaluate the initiation of tertiary flow for asphalt mixtures under dynamic creep test. Construction and Building Materials 23(11): 3398-3405.

Goh, S. W., You, Z., Williams, R. C. and Li, X. 2010. Preliminary dynamic modulus criteria of HMA for field rutting of asphalt pavements: Michigan's experience. Journal of Transportation Engineering 137(1): 37-45.

Grenfell, J., Ahmad, N., Airey, G., Collop, A. and Elliott, R. 2012. Optimising the moisture durability SATS conditioning parameters for universal asphalt mixture application. International Journal of Pavement Engineering. 13(5), 433-450.

Hicks, R. G. 1991. Moisture Damage in Asphalt Concrete. NCHRP Synthesis of Highway Practice, Vol.175, Transportation Research Board.

Hurley, G. and Prowell, B. 2006. Evaluation of potential processes for warm mix asphalt. J Assoc. Asphalt Paving Technol., 75, pp. 41-90.

Hurley, G. C. and Prowell, B. 2005. Evaluation of Aspha-Min Zeolite for Use in Warm Mix Asphalt. NCAT Report 05-04, National Center for Asphalt Technology, Auburn, AL.

Jimenez, R. A. 1974. Testing for debonding of asphalts from aggregates. Transportation Research Record 515, TRB, National Research Council, Washington, DC. 
Kanitpong, K. 2004. Evaluation of the roles of adhesion and cohesion properties of asphalt binders in moisture damage of HMA. Dissertation, University of Wisconsin -Madison Department of Civil and Environmental Engineering.

Kanitpong, K. and Bahia, H. U. 2003. Role of adhesion and thin film tackiness of asphalt binders in moisture damage of HMA. Asphalt Paving Technology, Vol. 72, pp. 502-528.

Khosla, N. P. and Harikrishnan, K. I. 2007. Tensile Strength- A Design and Evaluation Tool for Superpave Mixes. North Carolina Department of Transportation, FHWA/NC/2006-24.

Krishnankuttynair, H. 2008. Evaluation of Indirect Tensile Strength as Design Criteria for Superpave Mixtures. Ph.D,Thesis, North Carolina State University.

Little, D. N. and Jones IV, D. R. 2003. Chemical and Mechanical Processes of Moisture Damage in Hot-Mix Asphalt Pavements. Transportation Research Board National Seminar. San Diego, California, pp. 37-70.

Majidzadeh, K. and Brovold, F. N. 1966. Effect of Water on Bitumen-Aggregate Mixtures. University of Florida, Gainesville, Report CE-1.

Mallick, R. B., Gould, J. S., Bhattacharjee, S., Regimand, A. and Brown, E. R. 2003. Development of a Rational Procedure for Evaluation of Moisture Susceptibility of Asphalt Paving Mixes. Transportation Research Board, Washington DC.

Novak, M., Birgisson, B. and McVay, M. C. 2002. Effects of permeability and vehicle speed on pore pressure in hot mix asphalt pavements. Transportation Research Board Meeting, Washington, DC.

Rowe, G. M., Ranka, A., Ranka, M., Zuberer, D. and Thayer, J. 2015. Extended testing conditions for the evaluation of water sensitivity of HMA Mixes. $52^{\text {nd }}$ Petersen Asphalt Research Conference, Laramie, WY July 13 to 15. 
Tarrar, A. R. and Wagh, V. P. 1992. The effect of the physical and chemical characteristics of the aggregate on bonding. Strategic Highway Research Program Report SHRP-A/ UIR-91-507, Washington, DC.: National Research Council.

Terrel, R. L. and Al-Swailmi, S. 1994. Water Sensitivity of Asphalt Aggregate Mixes: Test Selection. SHRP-A-403, Strategic Highway Research Program, National Research Council, Washington, DC.

Woodward, D., Millar, P., Lantieri, C., Sangiorgi, C. and Vignali, V. 2016. The wear of Stone Mastic Asphalt due to slow speed high stress simulated laboratory trafficking. Construction and Building Materials. Vol. 110. Pages. 270-277. doi: 10.1016/j.conbuildmat.2016.02.031.

You, Z. and Dai, Q. 2007. Dynamic complex modulus predictions of hot-mix asphalt using a micromechanical-based finite element model. Canadian Journal of Civil Engineering /Rev 34(12): 1519-1528.

Zaniewski, J. 2006. Investigation of Moisture Sensitivity of Hot Mix Asphalt Concrete. Asphalt technology program department of civil and environmental engineering Morgantown, West Virginia 26506. 
Table 1: Gradations of Used Aggregates and Specifications

\begin{tabular}{|c|c|c|c|c|c|c|c|c|c|}
\hline Sieve Size & $1 \mathrm{in.}$ & $3 / 4$ in. & $3 / 8$ in. & No.4 & No.8 & No.30 & No.50 & No.100 & No. 200 \\
\hline Sandstone & 100 & 93 & 67 & 49 & 39 & 20 & 14 & 8 & 4 \\
\hline Gravel & 100 & 91 & 65 & 63 & 38 & 25 & 18 & 9 & 5 \\
\hline Dolomite & 100 & 98 & 62 & 52 & 35 & 21 & 16 & 7 & 4 \\
\hline Basalt & 100 & 91 & 61 & 48 & 35 & 19 & 18 & 9 & 3 \\
\hline Limestone & 100 & 85 & 65 & 60 & 42 & 29 & 20 & 10 & 6 \\
\hline Specifications & 100 & $80-100$ & $60-80$ & $48-65$ & $35-50$ & $19-30$ & $13-23$ & $7-15$ & $3-8$ \\
\hline
\end{tabular}


Table 2: Physical Properties of Used Asphalt Binder

\begin{tabular}{lll}
\hline Test & Results & Standard methods \\
\hline Penetration at $25^{\circ} \mathrm{C} 100 \mathrm{~g}, 5$ seconds, 0.1 mm & 66 & ASTM D5 \\
Softening Point (Ring and Ball), ${ }^{\circ} \mathrm{C}$ & 50 & ASTM D 36 \\
kinematic Viscosity at $135{ }^{\circ} \mathrm{C}, \mathrm{C} . \mathrm{st}$. & 355 & ASTM D 2170 \\
Absolute Viscosity at $60{ }^{\circ} \mathrm{C}$, poise & 250 & ASTM D 2171 \\
Retained Penetration $(\%)$ & 52 & ASTM D5 \\
Mass Loss $(\%)$ & 0.15 & ASTM D1754 \\
Ductility at $25{ }^{\circ} \mathrm{C}, 5 \mathrm{~cm} / \mathrm{min}, \mathrm{cm}$ & +110 & ASTM D1 13 \\
Flash Point, ${ }^{\circ} \mathrm{C}(\mathrm{Cleveland}$ Open Cup) & +255 & ASTM D92 \\
Specific gravity & 1.018 & ASTM D70 \\
Solubility in Trichloroethylene, $\%$ & 99.1 & ASTM D 2042 \\
\hline
\end{tabular}


Figure 1: Schematic Representation of the Proposed Conditioning System

Figure 2: Expected Relationship between ITS and Conditioning Time

Figure 3: Possible Failures of Asphalt Mixtures subjected to Moisture: (a) Cohesive Failure, (b) Adhesive Failure, and (c) Aggregate Degradation

Figure 4: Conditioning Process: (a) UTM, (b) Samples inside the Conditioning Unit, (c) Rubberized Sheet

Figure 5: ITS vs. Conditioning Time for Five Asphalt Mixtures

Figure 6: Air Voids vs. Conditioning Time for Five Asphalt Mixtures

Figure 7: $D_{\mathrm{r}}$ vs. TSR for Five Asphalt Mixtures: (a) after 30 min. conditioning, and (b) after an hour conditioning 


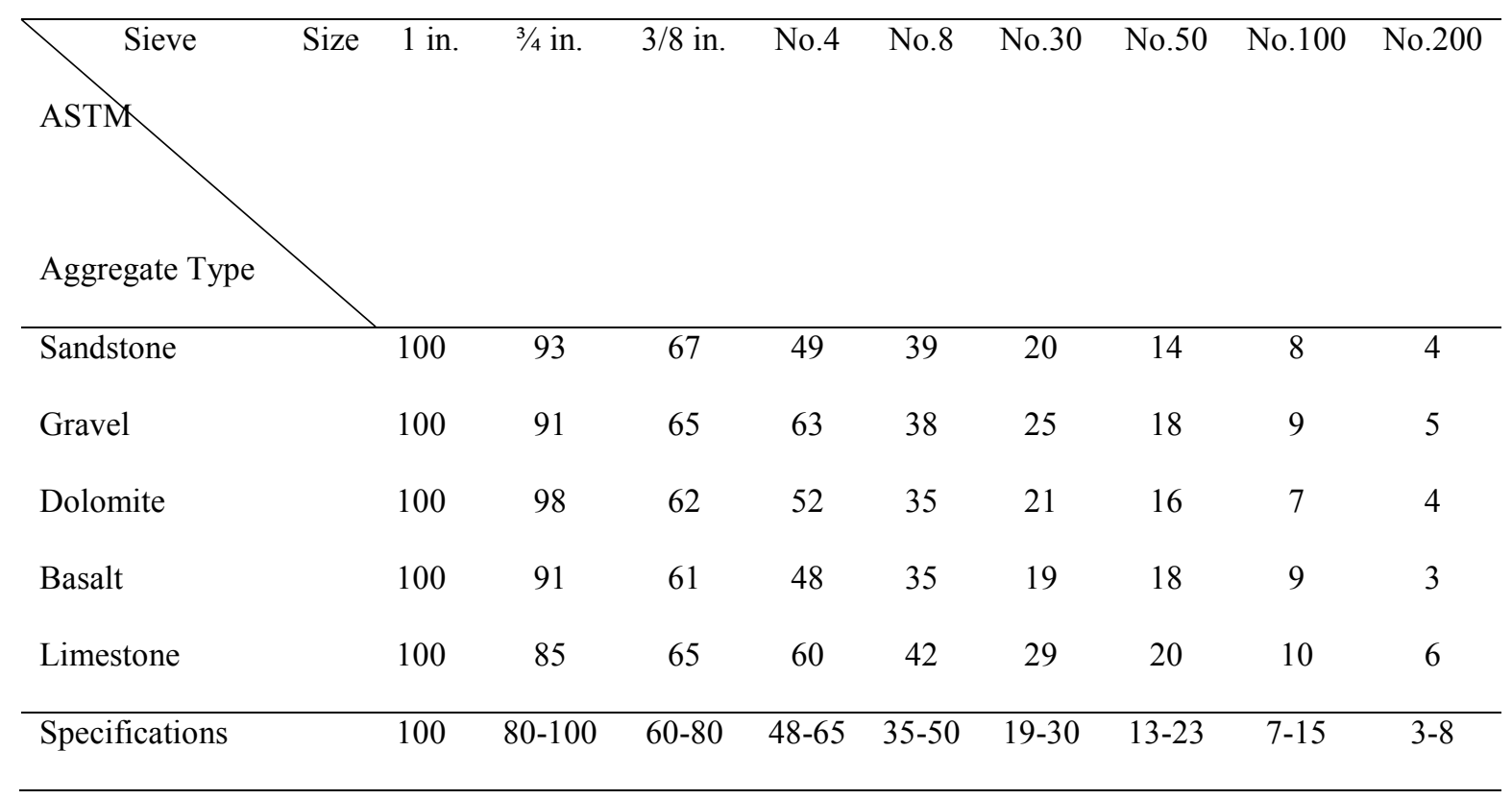




\begin{tabular}{lll}
\hline Test & Results & Standard methods \\
\hline Penetration at $25^{\circ} \mathrm{C} 100 \mathrm{~g}, 5$ seconds, $0.1 \mathrm{~mm}$ & 66 & ASTM D5 \\
Softening Point (Ring and Ball), ${ }^{\circ} \mathrm{C}$ & 50 & ASTM D 36 \\
kinematic Viscosity at $135^{\circ} \mathrm{C}, \mathrm{mPa} \cdot \mathrm{s}$ & 355 & ASTM D 2170 \\
Absolute Viscosity at $60^{\circ} \mathrm{C}$, poise & 250 & ASTM D 2171 \\
Retained Penetration (\%) & 52 & ASTM D5 \\
Mass Loss (\%) & 0.15 & ASTM D1754 \\
Ductility at $25^{\circ} \mathrm{C}, 5 \mathrm{~cm} / \mathrm{min}, \mathrm{cm}$ & +110 & ASTM D113 \\
Flash Point, ${ }^{\circ} \mathrm{C}(\mathrm{Cleveland}$ Open Cup) & +255 & ASTM D92 \\
Specific gravity & 1.018 & ASTM D70 \\
Solubility in Trichloroethylene, $\%$ & 99.1 & ASTM D 2042 \\
\hline
\end{tabular}




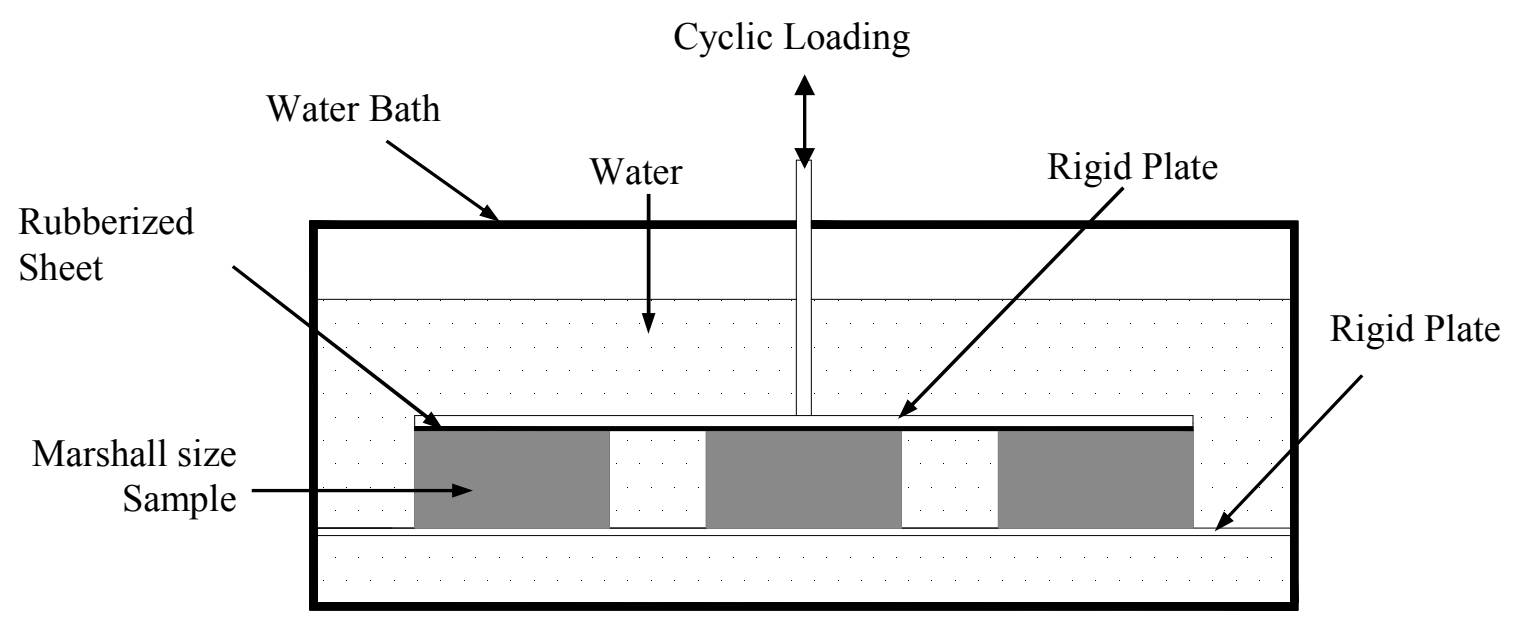









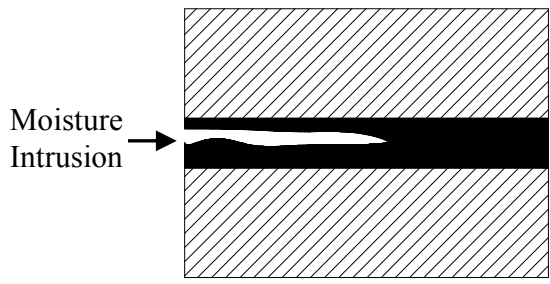

(a)



(b)

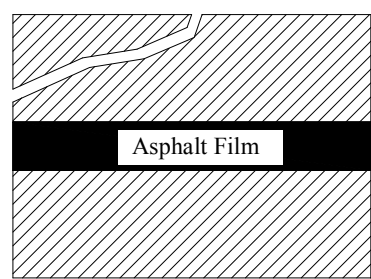

(c) 

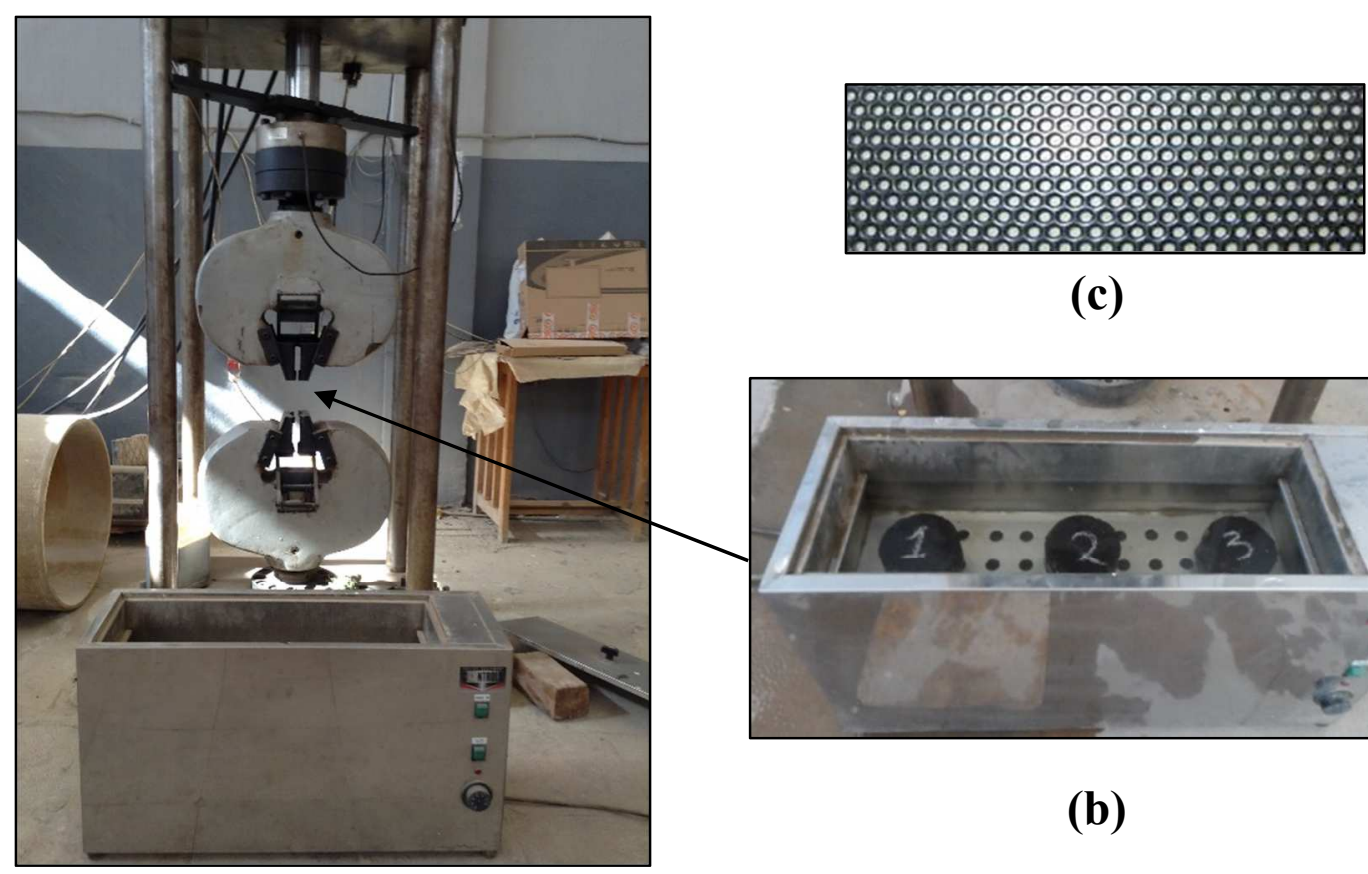

(c)

(a) 


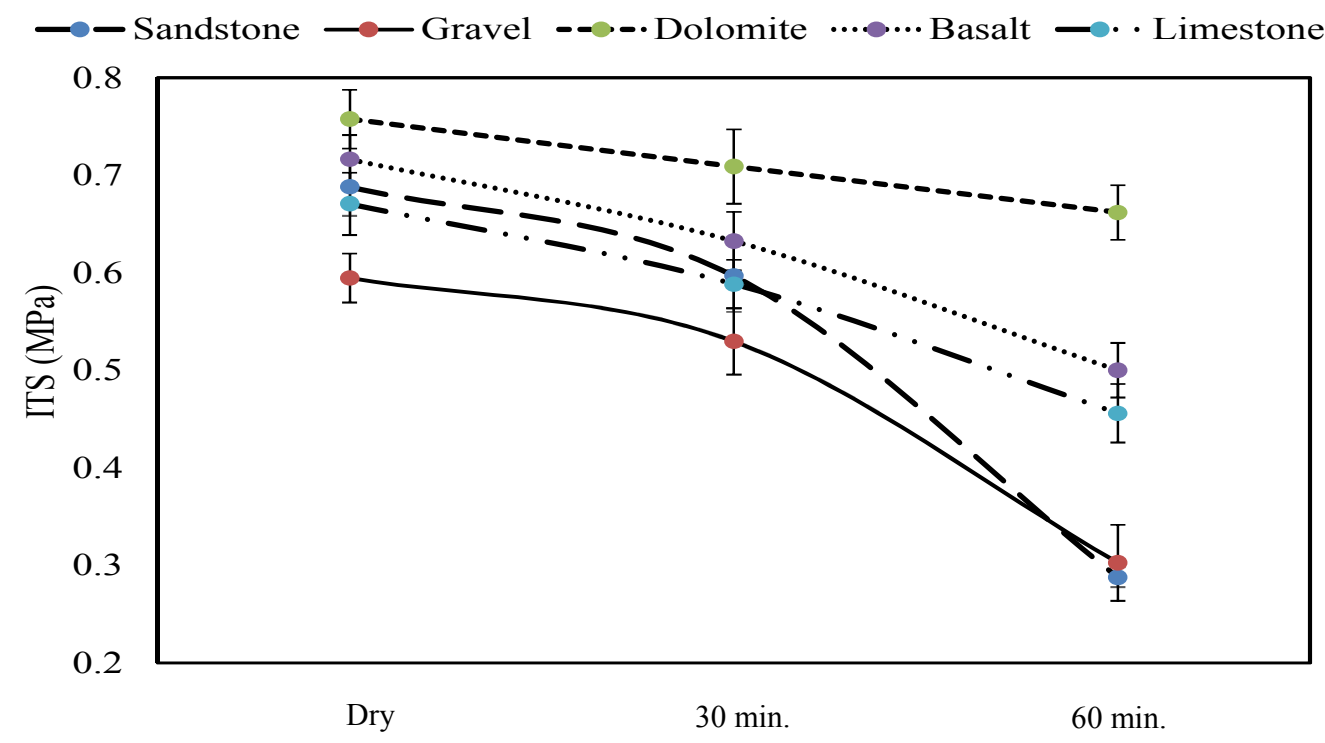







J Damage Rate /30 min. $\square$ TSR

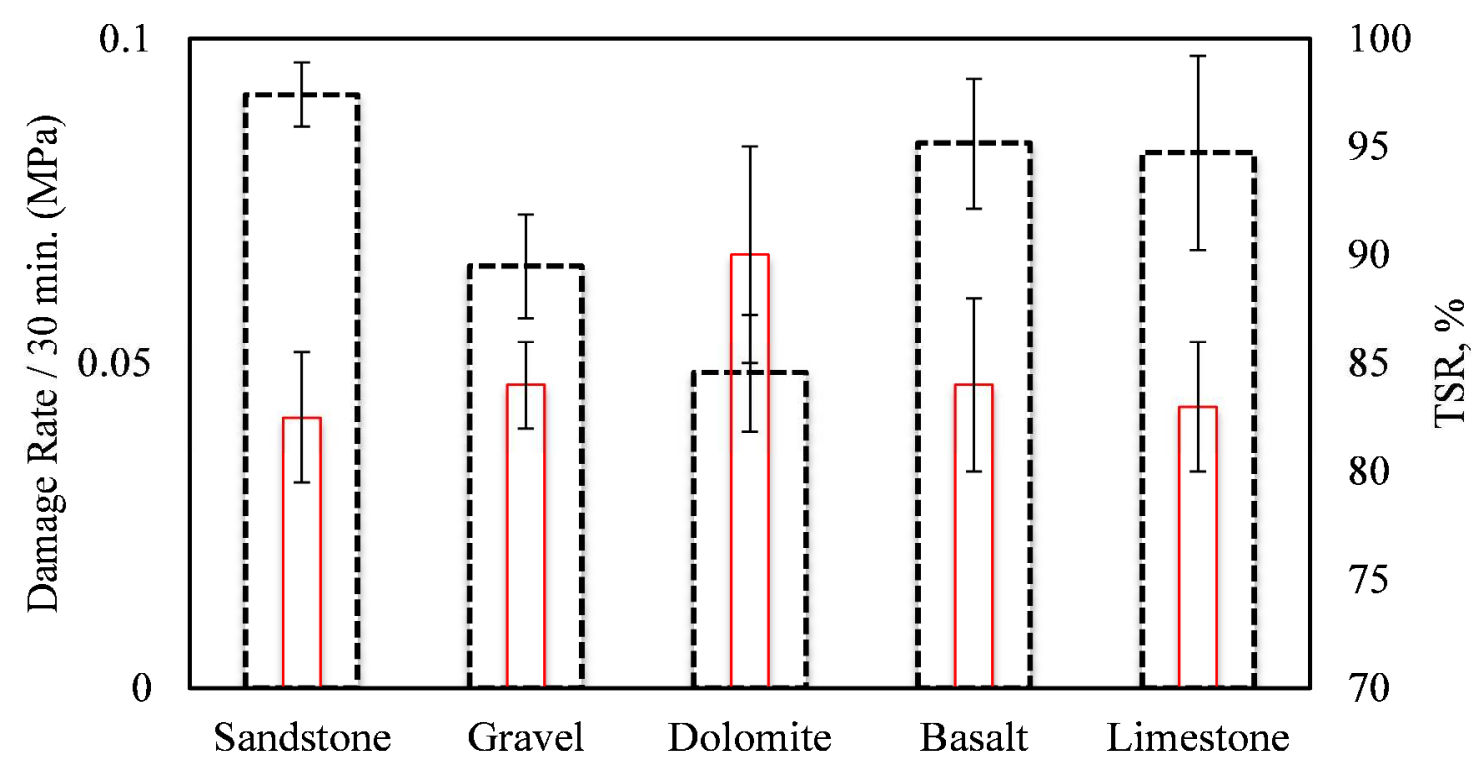

(a)

¿jDamage Rate /1 hr $\square$ TSR

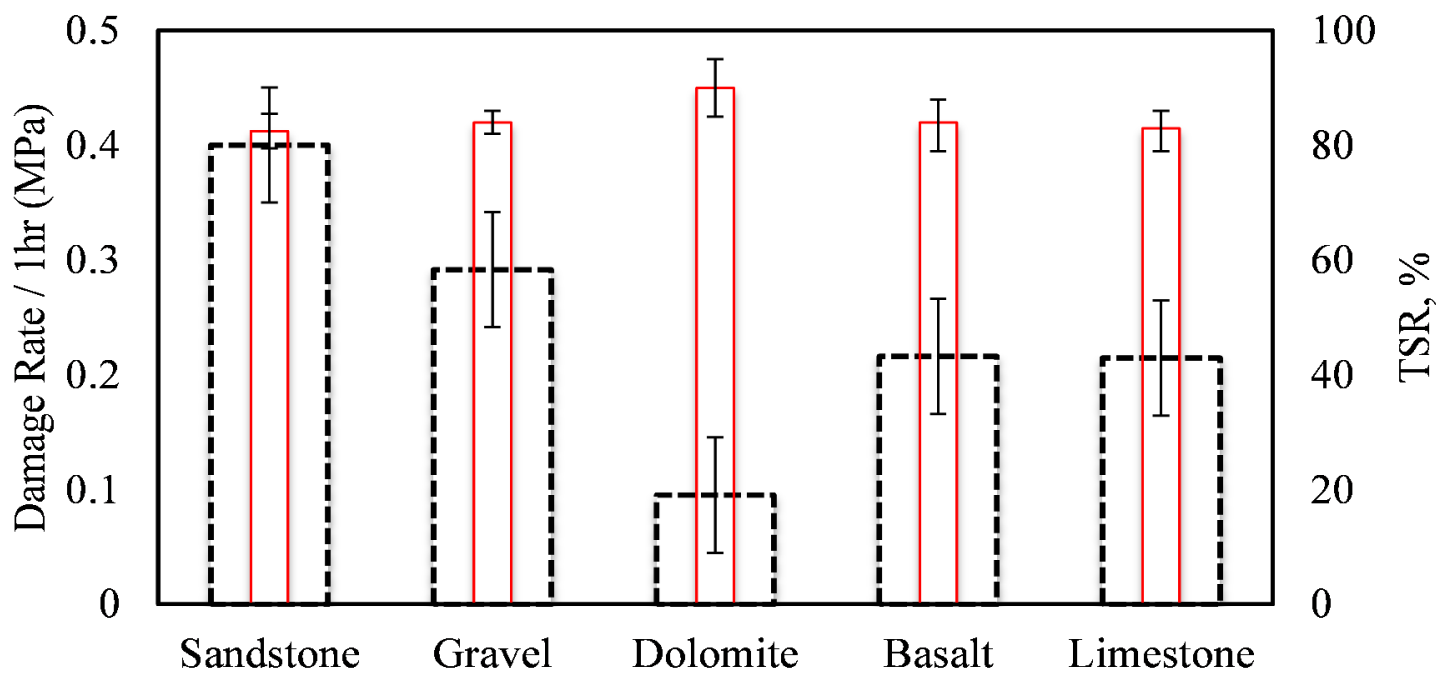

(b) 